\title{
TENDÊNCIAS CONTEMPORÂNEAS DA ARQUEOLOGIA PÚBLICA $x$ PATRIMÔNIO CULTURAL SUBAQUÁTICO
}

\author{
Contemporary Trends of Public Archaeology X Underwater Cultural Heritage \\ Daniel Martins Gusmão ${ }^{1}$
}

\section{RESUMO}

Com um litoral de aproximadamente $8.500 \mathrm{~km}$ de extensão, o Brasil apresenta um significativo Patrimônio Cultural Subaquático. Nesta miríade, submersa de conhecimentos arqueológicos, temos o seu potencial formado principalmente por restos de embarcações naufragadas, estruturas portuárias, espaços de religiosidade marítima, sítios santuários e sítios depositários. A partir da perspectiva contextual, este artigo tem como objetivo analisar o quadro teórico da ciência arqueológica, ressaltando as reflexões acerca do estilo público de se fazer Arqueologia numa análise voltada para o ambiente aquático.

Palavras-chave: Arqueologia, Patrimônio Cultural Subaquático, Arqueologia Pública.

\section{ABSTRACT}

With a coast of approximately $8.500 \mathrm{~km}$ of extension, Brazil has a significant Underwater Cultural Heritage. This submerged myriad of archaeological knowledge have the potential_formed mainly by rests of shipwrecks, port structures, maritime religiosity spaces, the sanctuary sites, and the depository sites. From the contextual perspective this article aims to analyze the theoretical framework of archaeological science highlighting the reflections about a public style of doing archeology in a focus and analysis to the aquatic environment.

Keywords: Archaeology, Underwater Cultural Heritage, Public Archaeology.

\section{RESUMEN}

Con un litoral de aproximadamente $8.500 \mathrm{~km}$ de largo, Brasil cuenta con un significativo patrimonio Cultural Subacuático. Esta experiencia miríada, sumergido arqueológico, tiene el potencial que consiste principalmente de restos de barcos naufragados, instalaciones portuarias, espacios de religiosidad marítima y sitios sagrados. Desde la perspectiva del contexto, este artículo tiene como objetivo analizar la imagen téorico de la ciencia arqueológica, destacando las reflexiones acerca de un estilo de hacer pública la arqueología en un análisis centrado en el medio ambiente acuático.

${ }^{1}$ Mestre em Arqueologia pela Universidade Federal de Sergipe (UFS), Linha Arqueologia de Ambientes Aquáticos. Historiador Naval e Arqueólogo Subaquático de carreira da Marinha do Brasil. Membro do Conselho Editorial da Revista Navigator: Subsídios para a História Marítima do Brasil. Membro do Laboratório de Arqueologia de Ambientes Aquáticos (LAAA/UFS) e membro do Grupo de Pesquisa do CNPq em Arqueologia de Ambientes Aquáticos. Contato: dmgusmao@yahoo.com.br 
Palabras clave: Arqueología, Patrimonio Cultural Subacuático, Arqueología Pública.

\section{CONSIDERAÇÕES INICIAIS}

O debate acerca das questõesque envolvem o Patrimônio Cultural Subaquático brasileiro, alinhada com a legislação divergente, as experiências de gestões malogradas e a falta de conhecimento do potencial que existe nos ambientes aquáticos fazem com que seja suscitada na sociedade certa apreensão, pelo simples fato de que, na maioria das vezes, a cultura material proveniente deste meio é desconhecida e não está acessível à grande maioria da população.

Com o propósito de discutir tal questão, apresantamos um palimpsesto de abordagens amparadas em distintas fontes teóricas. Incidimos na existência das interpretações ecléticas, pois acreditamos na coexistência de diferentes perspectivas que hoje abarcam a ciência arqueológica. Logo, essa composição de pontos de vistas torna-se essencial para o entendimento e significância de nossa proposta a partir de uma participação inclusiva do público na gestão do Patrimônio Cultural Subaquático e na concepção de uma consciência marítmia para a sociedade (FUNARI, 2010; RAMBELLI, 2003).

De acordo com Funari (2010:9), a Arqueologia é uma ciência que busca interpretar o passado através da cultura material e, a partir dele, entender as relações sociais e as transformações pelas quais as sociedades humanas se desenvolvem. A cultura material é o testemunho essencial das atividades humanas passadas, de forma que sua proteção e gerenciamento são indispensáveis para permitir aos arqueólogos estudá-la e interpretá-la. Trata-se, portanto, de uma ciência que está preocupada com "os sistemas socioculturais, sua estrutura, funcionamento e transformações com o decorrer do tempo, partir da totalidade material transformada e consumida pela sociedade" (Op. cit., p. 9).

Nesse campo de conceitos teóricos, diversos modelos de pensamento arqueológico vêm se desenvolvendo sobre o estudo das ações humanas. Há que se destacar as principais vertentes: o modelo Histórico-Culturalista, a Nova Arqueologia ou Processualismo e a Arqueologia Contextual ou Pós-Processualismo.

Herdeiro do nacionalismo do século XIX, o modelo Histórico-Culturalista se desenvolveu no século $\mathrm{XX}$, com fortes implicações racistas, explicando as mudanças culturais como causadas externamente ao indivíduo. Gordon Childe, um dos principais arqueólogos desse período, excluiu os pressupostos racistas, aplicando no conceito de 
cultura material um viés do evolucionismo marxista, definindo-a como homogênea com tradições que são passadas de geração em geração e explicando as mudanças culturais através de migrações de povos ou difusão geográfica das culturas (FUNARI, 2010; TRIGGER, 2004).

A partir da década de 1960, arqueólogos estadunidenses e britânicos passaram a criticar o modelo até então vigente, visando atribuir à Arqueologia um caráter científico com explicações e interpretações dos processos culturais de maneira generalizadora, o que contribuiu para a denominação dessa nova corrente teórica de processualismo, tendo como principais expoentes Lewis Binford, David Clarke e Colin Renfrew. Também conhecida como Nova Arqueologia, essa teoria sofreu influências do neo-evolucionismo, por meio da Antropologia. Baseando-se na teoria geral dos sistemas e no positivismo lógico, seu foco principal consiste na identificação e na explicação dos processos culturais no registro arqueológico, considerando a utilização da ciência em contraponto à geração anterior de arqueólogos (FUNARI, 2010; JOHNSON, 2000).

Reticentes com as abordagens processualista e histórico-culturalista, que ainda continuam em plena atividade nos dias atuais, arqueólogos, tendo à frente lan Hodder, começaram, a partir do final da década de 1970, autilizar um novo enfoque envolvendo as ciências humanas e com tendências contemporâneas, tais como a Sociologia, o pensamento Estruturalista, a Filosofia e o Marxismo, entre outras procedências, com 0 objetivo de entender a forma de pensar das sociedades. Esse campo teórico deu vez à dimensão dos significados simbólicos em diferentes contextos culturais, retomando para a Arqueologia a discussão de problemas de caráter histórico a partir das representações coletivas e das estruturas mentais da sociedade, incluindo o arqueólogo na análise e interpretação dos dados. A ação dos arqueólogos, enquanto construtores do passado a partir de sua classe social, ideologia, cultura e gênero é o ponto de partida para as perguntas que se formulamàs evidências arqueológicas, isto é, há um contexto em se valorizar o compromisso com a sociedade, tido como um processo social contemporâneo entre arqueólogos e as comunidades afetadas pelo registro arqueológico (HODDER e HUTSON, 2003; JOHNSON, 2000).

Essa nova proposta, denominada de Arqueologia Pós-Processual ou Contextual, trouxe como um de seus principais articuladores, o arqueólogo lan Hodder que defendeu um conjunto sistemático de ideias, com o objetivo de aprofundar aindamais a questão metodológica, restringindo-se não apenas à concepção adaptativa da cultura e à aplicação da Teoria de Sistemas, mas valorizando também o compromisso com a sociedade, o que 
passou a ser um dos pilares desse novo campo teórico, incluindo o processo social contemporâneo e as comunidades participativas no registro arqueológico.

A partir de seus objetos de estudo, a Arqueologia pode contribuir para a compreensão e crítica do presente. O mundo material é a substância a partir da qual as pessoas criam seus próprios textos biográficos significativos. Dessa forma, as coisas são mais do que simples adereços na criação de vidas significativas: elas adquirem vida própria (HODDER e HUTSON, 2003).

Há uma relação dialética entre passado e presente: o passado é interpretado a partir do presente, mas o passado também pode ser usado para criticar e questionar o presente. Dessa forma, é possível avaliar de forma crítica contextos passados e presentes em relação uns aos outros, de modo a se obter uma melhor compreensão de ambos. Há uma capacidade mental humana para conceber mais do que um contexto subjetivo e avaliar criticamente a relação entre as perspectivas variadas (HODDER e HUTSON, 2003). Assim, a Arqueologia busca, através dessa abordagem,a mediação entreo passado e o presente, salientando ainda a importânciadas interpretaçõesarqueológicas no presente.

A partir dessa última abordagem e diante da realidade ameaçadora do Patrimônio Cultural Subaquático no Brasil e a partir de um enfoque da participação pública na proteção e preservação dos sítios arqueológicos formados por restos de embarcações naufragadas e/ou abandonadas temos a intenção de

sensibilizar e conscientizar a sociedade brasileira, através da Arqueologia Subaquática, sobre a importância dessa cultura material - patrimônio cultural subaquático -, que está ameaçada de desaparecer literal e oficialmente, debaixo de nossos olhos, para a construção de nossa identidade nacional (RAMBELLI, 2003:24).

Para Hodder e Hutson (2003), as novas teorias que valorizam o compromisso com a sociedade despertaram maior interação entre arqueólogos e as comunidades impactadas pelos registros arqueológicos. Assim, a partir de um processo inclusivo é necessário dialogar com as comunidades marítimas, compostas principalmente por mergulhadores recreativos, operadoras de mergulho, pescadores e população costeira, com o intuito de despertar nestes setores maior conscientização marítima e incutir nestes segmentos a importância da valorização do Patrimônio Cultural Subaquático.

A partir de discussões no contexto das relações entre o indivíduo e a sociedade, as abordagens de acordo com percepções individuais conduzem a uma curiosa revira volta na reconstrução do conteúdo de significados históricos, possibilitando que um mesmo objeto tenha significados diferentes ou até mesmo conflitantes, a partir de diferentes dimensões de variação e de perspectivas (HODDER e HUTSON, 2003). Percebemos estas diferenças na 
construção dos significados, notadamente em estudos realizados a partir dos restos de embarcações naufragadas - que podem ser interpretados apenas como "naufrágios", locais para atividades de mergulho recreativo, que propiciam visitas em busca de souvernirs, ou ainda como "cascos soçobrados", regiões perigosas à navegação que devem ser evitadas pelas embarcações.

A importância dos contextos histórico e cultural contribui ativamente para o processo de interação entre o homem e o mundo que o cerca. Dessa forma, a cultura material pode ser vista como um meio de comunicação e expressão, que pode condicionar e, eventualmente, controlar, a ação social, permitindo que o indivíduo possa contribuir para a interpretação do registro arqueológico.

A partir desse ponto de vista, a nossa preocupação se volta para a necessidade de transformar os sítios arqueológicos subaquáticos em "grandes expressões monumentais e simbólicas do processo de formação da sociedade brasileira" (RAMBELLI, 2003:149), uma vez que esses locais podem denotar potencial relevante para a sociedade que os cerca, principais beneficiários da sua existência, embora não tenham a percepção desta significância. Desta maneira, a inclusão do público na prática arqueológica e no discurso em prol da proteção do patrimônio arqueológico submerso é primordial e necessária.

\section{A ARQUEOLOGIA TRANSPARENTE}

Conforme Mckee (2002:512) a expressão "Arqueologia Pública" surgiu na década de 1960, geralmente relacionada à gestão de recursos pelo Estado em terras públicas ou em terras sujeitas à regulamentação governamental, e, geralmente, apoiado por fundos públicos. Ao longo dos anos, o seu uso e significado se ampliaram, e agora descreve a pesquisa arqueológica que inclui qualquer tipo de envolvimento com o público. Com o passar dos anos, seu significado e uso têm-se ampliado bastante, de forma que, atualmente, a Arqueologia Pública inclui qualquer tipo de engajamento com o público, seja ocasional ou por meio de programas educacionais, publicações e exposições que ofereçam oportunidades e parcerias com os grupos descendentes e com laços específicos sobre os sítios arqueológicos envolvidos (Op. cit., p. 512). Dessa forma, se deseja como resultado um programa de Arqueologia Pública que possa integrar a comunidade, permitindo que ela participe da construção do conhecimentoe e crie uma conscientização marítima a partir de sua relação de pertencimento com os sítios arqueológicos subaquáticos (BAUMANN, 2002). 
Ao se pensar em Arqueologia Pública, devemos ter em mente questões sobre a atitude do público em relação ao patrimônio e, não apenas a divulgação de resultados de pesquisas acadêmicas/científicas, que é um dos pressupostos de qualquer ciência, pois

\begin{abstract}
a ciência produz conhecimentos para a sociedade e não para si mesma. $A$ Arqueologia Pública, tal como a compreendemos, engloba um conjunto de ações e reflexões que objetiva saber a quem interessa o conhecimento produzido pela Arqueologia; de que forma nossas pesquisas afetam a sociedade; como estão sendo apresentadas ao público, ou seja, mais do que uma linha de pesquisa da disciplina, a Arqueologia Pública é inerente ao exercício da profissão (BEZERRA DE ALMEIDA, 2003: 276).
\end{abstract}

Nas últimas décadas, a apresentação da Arqueologia para o público passou a ser uma importante ferramenta de divulgação e conscientização da necessidade de se conhecer para preservar. A crescente degradação do Patrimônio Cultural Subaquático, seja ela ocasionada por processos naturais ou culturais e principalmente pelo desenvolvimento econômico, é o resultado de uma relação distorcida entre opúblico e o patrimônio arqueológico. Nesse sentido, muitas pessoas defendem a Arqueologia como uma atividade importante, porém exótica, que desperta curiosidade. No entanto, o dever profissional do arqueólogo deve ultrapassar esses meandros, pois entendemos que:

Nosso compromisso profissional passa pelo imperativo de mostrar ao público uma Arqueologia que, longe de ser uma atividade de entretenimento, seja um instrumento na construção de sua memória, de sua história, de sua identidade e de sua cidadania. (BEZERRA DE ALMEIRA, 2003: 276).

A partir surgimento do World Archaeological Congress (WAC), (nota: No 11ำ encontro da UISPP de 1986, ocorrido em Southampton, deu-se a cisão que dará origem ao WAC. Tal cisão está relacionada à cobrança, por parte de alguns membros, de um posicionamento político diante do Apartheid), a Arqueologia Pública passou a ser tratada, no Brasil, de forma mais sistemática, propiciando o relacionamento entre a pesquisa e a gestão de bens culturais de grupos sociais interessados. Assumindo uma responsabilidade social, busca-se a construção de uma opinião pública centrada com a questão da defesa do Patrimônio Cultural Subaquático (FUNARI e ROBRAHN-GONZÁLES, 2008; RAMBELLI, 2008).

A realidade brasileira contemporânea é marcada por uma multiplicidade de vertentes dos usos pragmáticos da Arqueologia Pública. Podemos resumir essa experiência em três modelos. No "primeiro modelo", o da Educação, a Arqueologia é tida como uma ciência neutra e exata, um instrumento de educação para as massas. Já o "segundo modelo" identifica-se com a ideia de que; a partir do aval social busca-se uma relação

v.9 n. 2 
pública para melhorar a imagem da Arqueologia na sociedade, bem como 0 desenvolvimento de suas pesquisas arqueológicas. Por fim, o "modelo democrático", defende que todas as pessoas envolvidas são detentoras de conhecimentos válidos, que variam de acordo com a trajetória de vida de cada um dos indivíduos, de modo que essa variabilidade é relevante na construção do conhecimento (HOLTORF, 2007, Apud CARVALHO; FUNARI, 2009:4).

Nesse ponto, destacamos ainda Camila Wichers (2011:71), ao enfatizar que "não existe uma Arqueologia Pública, mas diferentes Arqueologias Públicas", com base numa diversidade de experiências aplicadas por meio de uma correlação dos modelos relacionados acima.

No Brasil, a Arqueologia Pública vem abordando uma temática do fazer arqueológico de forma crítica, inserida em sua proposta contextual. Marcada por experiências de influências em que se busca uma abordagem de interesse público, essas ações que visam "ensinar o que é Arqueologia, obter a aprovação das pesquisas pelas comunidades envolvidas ou ainda corrigir visões acerca da prática arqueológica" apresentam abordagens estruturadas por modelos de Educação e de Relação Pública (WICHERS, 2011:74).

Com o surgimento do primeiro número da Revista de Arqueologia Pública, editada no Brasil desde 2006 pelo Núcleo de Estudos Estratégicos da Universidade Estadual de Campinas (NEE/UNICAMP), vinte anos após o WAC, apresentou uma visão que influenciou o panorama da Arqueologia Pública brasileira, destacando em seu editorial que:

No Brasil, a expressão Arqueologia Pública, surgida em âmbito anglosaxão, ainda é nova e pode levar a confusão. De fato, público, em sua origem inglesa, significa 'voltada para o público, para o povo' e nada tem a ver, stricto sensu, com o sentido vernáculo de público como sinônimo de 'estatal'. Ao contrário, o aspecto público da Arqueologia refere-se à atuação com as pessoas, sejam membros de comunidades indígenas, quilombolas ou locais, sejam estudantes ou professores do ensino fundamental ou médio. A ação do Estado dá-se, de maneira necessária, por meio da legislação de proteção ambiental e cultural que leva empreendedores empresas privadas ou públicas - a custearem estudos de impacto ambiental e cultural. Nem sempre tais estudos visam à ação pública, no sentido mencionado acima, de interação com as pessoas. Do nosso ponto de vista - e esta revista serve a este propósito - a ciência não deve alhearse da sociedade, sob o manto diáfano do empirismo. A Arqueologia Pública, entendida como ação com o povo, para usarmos uma expressão de Paulo Freire, permite que tenhamos uma ciência aplicada em benefício das comunidades e segmentos sociais. (FUNARI \& ROBRAHNGONZÁLES, 2006:3).

Esse panorama nacional abre espaço para reflexões que envolvem a Arqueologia Pública, essencialmente, a participação comunitária. Para McKee (2002),essas atividades, 
bem como a inserção das comunidades diretamente afetadas pelo registro arqueólogico, são impulsionadas pela ideia de queessa interação constitui uma responsabilidade ética por parte do pesquisador, que passa a ter oportunidades de divulgar a notícia de descobertas e interpretações mais amplas dos dados, além da possibilidade de reunir mais informações sobre os locais e os temas em estudo.

Ainda com relação à necessidade de divulgação da Arqueologia Subaquática no intuito de se buscar o interesse do público geral e trazê-lo para os debates acerca da proteção do Patrimônio Cultural Subaquático,concordamos que

\begin{abstract}
o primeiro ponto que deve ser pensado são questões de publicações de obras e textos sobre Arqueologia Subaquática em vários locais e com um texto acessível para o grande público. Obras que divulgam a ciência em si, como o caso do livro Arqueologia Até Debaixo D'Água, do arqueológo Gilson Rambelli (2002), são de grande importância no que concerne a divulgar a disciplina e a chamar a atenção do público-leitor para alguns de seus debates internos. Além disso, textos escritos por especialistas diversos divulgados em site de conteúdo aberto, em revistas voltadas para um público em geral, e a disponibilidade de um manifesto, como o Livro Amarelo (2004), para download, sem dúvida, inserem um amplo público na temática. (FONTOLAN, 2012:33).
\end{abstract}

De forma semelhante, defendemos a visão de Fontolan, pois faz-se necessário ressaltar o enfoque da Arqueologia na sociedade, trazendo para si a responsabilidade de tornar o conhecimento científico acessível a todos.

\title{
O “ESTILO PÚBLICO” DE SE FAZER ARQUEOLOGIA
}

Ao longo das duas últimas décadas, a natureza e o grau deenvolvimento do público tornaram-se fonte de acalorada discussão entre arqueólogos. A discórdia nasce em torno de diferentes modelos de atuação do arqueólogo. Em um deles, o papel do público é o de um espectador relativamente passivo, enquanto outra concepção vê o público como parceiros ativos e com interesse vital para orientar o curso da investigação e interpretação do passado (MCKEE, 2002).

A Arqueologia Pública deve ser encarada como uma questão de ética profissional e abertura temática, tendo como foco principal a responsabilidade social do arqueólogo. Cabe destacar que essa responsabilidade social não se aplica somente às situações de conflito social, mas deve ser exercitada também no dia a dia do cientista.

A partir de um enfoque de excursionismo e entretenimento, podemos destacar que

O turismo arqueológico tem servido como uma das principais alternativas de "preservação pela apreciação", tanto por seu forte apelo a estética como mercadoria, quanto por sua inevitável presença no litoral dos mais diversos

v.9

n. 2 p. $72-86$ 
países do mundo, desde que "ir a praia" está entre as principais recreações do indivíduo moderno. (SILVA, 2010:70).

Para conformação destas ideias, deve-se ter como um dos primeiros objetivos do arqueológo o desafio de aproximar o público alvo dos ambientes aquáticos (mergulhadores esportistas, navegantes e comunidades pesqueiras) das questões inerentes à preservação e proteção do Patrimônio Cultural Subaquático. Com relação à aproximação entre o público e a Arqueologia, as principais dificuldades do arqueólogo engajado foram que

\begin{abstract}
comum conhecimento tão fraco sobre as atitudes, concepções e crenças dos receptores da informação arqueológica, os arqueólogos foram, portanto,comunicando cegamente a um público que não entende,e não é de se admirar que tantas tentativas de comunicações arqueológicas tenham resultado em tédio ou incompreensão. Em termos de compreensão do público, então,a Arqueologia tem muito a aprender com a compreensão pública da ciência (MERRIMAN, 2004:8, tradução pessoal).
\end{abstract}

Os desafios relacionados à questão da preservação e proteção do Patrimônio Cultural Subaquático suscitam debates veementes. A esse respeito, Rambelli (2009b:72) destaca que "uma reflexão sobre o futuro de nosso patrimônio cultural subaquático se faz urgente e necessária", pois a ameaça a esse patrimônio no Brasil, sobretudo com relação a sítios arqueológicos de naufrágios, relaciona-se diretamente com a maneira através da qual as pessoas enxergam esse patrimônio e se relacionam com ele. Algumas vezes, essa relação é passional, constituída de visitas e contemplações, enquanto em outras situações a relação com o patrimônio mostra-se bastante intrusiva e violenta, como é o caso de colecionadores de souvenires e caçadores de tesouro.

$\mathrm{Na}$ tentativa de unir segmentos da sociedade que se envolvem em atividades no ambiente aquático, seja por lazer ou trabalho, os arqueólogos têm buscado convergir esses grupos com políticas de preservação do Patrimônio Cultural Subaquático. No final dos anos 1980, por exemplo, o Projeto ARCHEMAR - Centro de Pesquisa e Referência em Arqueologia e Etnografia do Mar $^{2}$ esboçou uma proposta a esse respeito, que não obteve êxito (RAMBELLI, 2002).

\footnotetext{
${ }^{2}$ O Projeto ARCHENAVE - (Programa de Pesquisa sobre Arqueologia, História e Etnografia Navais da Costa Brasileira) - esboçou uma política de preservação e estudo do patrimônio naval em nível nacional, dividindo a costa brasileira em seis áreas culturais navais. O programa compreendia uma proposta inovadora de proteção e gestão do Patrimônio Cultural Subaquático para a época, no entanto, foi uma iniciativa que, embora apresentasse uma preocupação interessante, acabou não se concretizando de fato.
} 
Nos últimos anos, a artista plástica baiana Lica Moniz de Aragão lançou o Projeto Maraldi ${ }^{3}$ com objetivo de se apropriar do patrimônio submerso, através de uma perspectiva contemplativa, proporcionando ao público a possibilidade de visualizar um sítio arqueológico do naufrágio Maraldi, na Baía de Todos os Santos (Salvador - BA) iluminando-o à noite. Concebido como um encontro entre a linguagem visual contemporânea e a arqueologia marítima, a artista destaca que o seu trabalho

Inserido no contexto das poéticas visuais contemporâneas e constituído por uma apropriação artística submarina site specific, o projeto Maraldi promove discussões e reflexões entre arte e arqueologia de naufrágios, dilatando a dimensão estética das poéticas líquidas e incentivando a preservação dos bens culturais que constituem nossa história [...]. O projeto Maraldi traz a tona a importância dos sítios arqueológicos de naufrágios, considerados pelos pesquisadores da área como um acervo oculto, pouco estudado e de grande valor histórico. Esses sítios constituem bens culturais de alta relevância enquanto memória, identidade e patrimônio. (ARAGÃO, 2010)

Ao problematizar essas questões, percebemos que o estreitamento da relação entre sociedade e patrimônio arqueológico é de vital importância para a sustentação de medidas de preservação. Aproveitando-se ainda da notoriedade da Arqueologia, destacamos que

Um dos benefícios públicos da Arqueologia está justamente em contribuir para o fortalecimento dos vínculos existentes entre a comunidade e seu passado, ampliando o interesse da sociedade sobre o patrimônio e criando, assim, a sustentação necessária às medidas de preservação (grifo nosso). Nessa empreitada devemos explorar o grande interesse e fascínio que a Arqueologia desperta nas pessoas, por conta de seu perfil de descobertas e da busca pelo passado. De fato, a Arqueologia parece constituir a segunda profissão de mais da metade da população. Frequentemente nos deparamos com frases como "se eu não fosse engenheiro (ou médico, ou professor, ou qualquer outra profissão), seria arqueólogo" (ROBRAHN-GONZÁLES, 2006:65).

Esse trecho destaca medidas que buscam a preservação do patrimônio arqueológico que podem ser sustentadas através da conscientização da sociedade. Como se preservar o que não se conhece? É necessário, primeiramente, mostrar para a sociedade a importância do potencial arqueológico existente, para, a partir daí, refletir sobre a necessidade de perpetuar a existência deste patrimônio.

${ }^{3}$ O sítio arqueológico Maraldi, denominação do cargueiro a vapor britânico, que afundou em 1875, entre os Fortes de Santo Antônio e o Forte de Santa Maria, na Baía de Todos os Santos (Salvador $\mathrm{BA}$ ), e os seus restos encontram-se numa profundidade média dos 4 aos 12 metros foi objeto de uma apropriação artística da artista plástica LicaMonis de Aragão, onde a artista buscou "acender" o sítio arqueológico demarcando o local com luzes estanques, dando visibilidade ao patrimônio submerso. 
No início da década de 1990, os debates sobre até que grau a Arqueologia deveria se tornar verdadeiramente pública foram estimulados pelo ativismo emergente de grupos de pessoas diretamente ligadas aos temas da análise arqueológica. Considerada necessária para o desenvolvimento da Arqueologia, essa interação coletiva tem fomentado um crescente diálogo com historiadores, antropólogos e outros acadêmicos que estudam essas temáticas (FUNARI, 2002; MCKEE, 2002).

McKee (2002) destaca que uma abordagem verdadeiramente pública para a pesquisa arqueológica deve começar por ver o público não apenas como um agente receptivo das descobertas e interpretações da Arqueologia, mas como um cooperador que tem suas reivindicações legítimas diante da propriedade intelectual gestada a partir do registro arqueológico e dos resultados da pesquisa, pois

\begin{abstract}
Não há pesquisa, nem mesmo pré-histórica, que esteja fora dos interesses da sociedade e a Arqueologia pode ser profundamente humanista, particularmente relevante para uma sociedade multicultural, sempre que atue com a humanidade. Nesse caso, o engajamento do intelectual não the subtrai qualquer conhecimento, ao contrário, pois "conhecer" é "saber com" os outros. Tornar-se arqueólogo inclui, assim, saber que não há trabalho arqueológico que não implique em patrimônio e em socialização do patrimônio e do conhecimento. (FUNARI, 2010:109).
\end{abstract}

Atualmente, um dos principais obstáculos para muitos arqueólogos consiste na dificuldade de canalizar o envolvimento do público em seus trabalhos, bem como no grau de poder decisório que esse público terá em suas considerações. As oportunidades oferecidas ao público para participar de escavações, visitar sítios e ouvir resultados e conclusões sobre a pesquisa arqueológica não é o suficiente? Ou os arqueólogos devem avançar mais além, propiciando ao público uma verdadeira interação e poder de decisão sobre a direção e interpretação da pesquisa arqueólogica? Envolver o público leigo na prática arqueológica constitui "um desafio para o arqueólogo brasileiro e a razão última para nossa ação é trabalhar para e com tais públicos" (FUNARI; OLIVEIRA; TAMANINI, 2008:131).

Acreditamos que deve haver maior aproximação entre a Arqueologia e a sociedade por meio de iniciativas que incluam a participação ativa dos indíviduos, permitindo que os arqueólogos exerçam uma parte essencial de sua atividade: a responsabilidade social. Caso contrário, qual seria o papel social do arqueólogo se não resguardar patrimônio cultural em benefício da coletividade? (FUNARI; OLIVEIRA, TAMANINI, 2008; RAMBELLI, 2009a).

O engajamento do arqueólogo com o público visa encorajar a realização pessoal e enriquecer as vivências individuais, estimulando a reflexão e a criatividade. A vantagem dessa abordagem para a Arqueologia Pública é o reconhecimento da "ação social" na

\begin{tabular}{|l|l|l|l|l|l|l|}
\hline C Rev. Arqueologia Pública & Campinas, SP & v.9 & n.2 & p.72-86 & DEZ-2015 & ISSN 2237-8294
\end{tabular}


reinterpretação e renegociação de significados. $O$ trabalho ativo através dessa percepção, que considera a Arqueologia e o público, a nosso ver, é a orientação mais apropriada para o estímulo do uso social do patrimônio arqueológico, diante das múltiplas possibilidades de "informações únicas" e "não renováveis" que se perdem cotidianamente dos sítios arqueológicos de naufrágios explorados na costa brasileira (MERRIMAN, 2004; RAMBELLI, 2008).

A essa práxis significativa da Arqueolagia pública, McKee (2002) chamou de "public style", que consiste em se promover a Arqueologia, reconhecendo os diversos segmentos públicos que se projetam dentro e fora da disciplina. Esses segmentos devem ser vistos como igualmente importantes e dignos de atenção, mas com diferentes necessidades em termos de estilos e detalhes aos quais devemos nos ater ainda mais.

A abordagemdo estilo público de ser fazer Arqueologia também leva em contaas conversas com o público dentro e fora do sítio, ao invés de palestras ou apresentações roteirizadas. As conversas são, naturalmente, trocas nos dois sentidos, tanto na escuta quanto na fala, na representação e no significado, com mecanismos efetivos de comunicação e interpretação que visem à construção democrática de diálogos entre a sociedade e seus patrimônios, possibilitando ao indíviduo compreender a importância desse patrimônio (FUNARI e CARVALHO, 2011).

Essa aproximação entre a Arqueologia Pública e o patrimônio cultural submerso é bem delineada por Bruno Silva, que nos chama a atenção para a necessidade de negociação do espaço, entre o patrimônio e seu uso social. No caso da promoção e organização das atividades de lazer, ou seja, de atividades turísticas, o autor argumenta que:

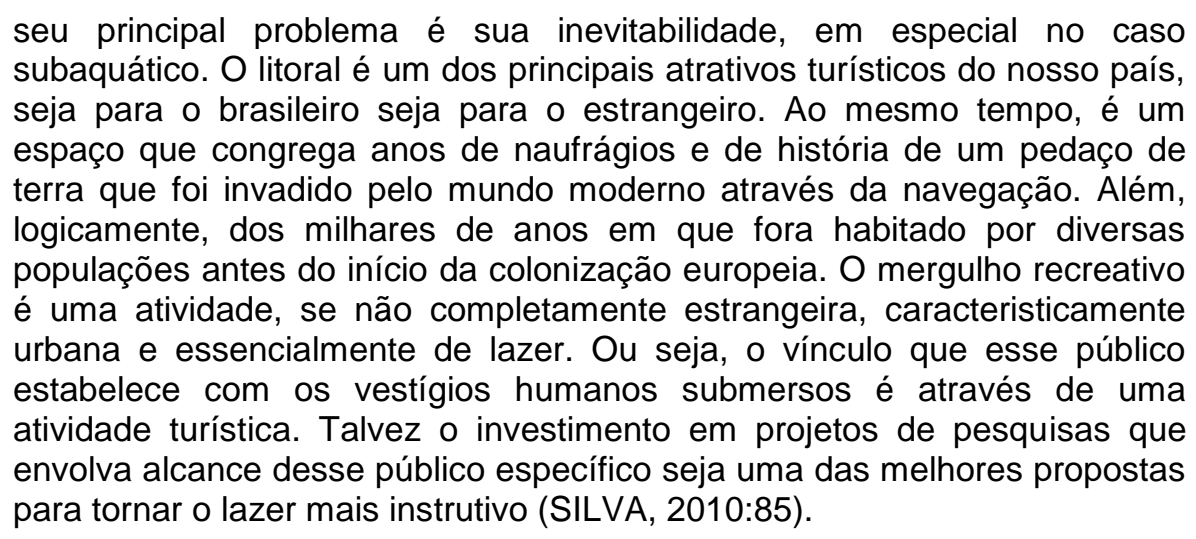

A partir de uma definição mais ampla da expressão Arqueologia Pública e, considerando-se que há uma tendência da inserção de diversos segmentos da sociedade na Arqueologia, de acordo com a perspectiva brasileira, também acreditamos na integração

\begin{tabular}{|l|l|l|l|l|l|l|}
\hline (C) Rev. Arqueologia Pública & Campinas, SP & v.9 & n.2 & p.72-86 & DEZ-2015 & ISSN 2237-8294
\end{tabular}


do público na proposta de construção e conscientização pela importância do Patrimônio Cultural Subaquático. Essa opção visa não só ouvir o público, mas atraí-lo para a construção desse conhecimento, levando em conta seus interesses e contradições. Dessa forma, buscamos construir uma Arqueologia transparente, concebida por múltiplas visões e compreendendo o constante campo de tensões que existe na apropriação do Patrimônio Cultural Subaquático.

\section{AGRADECIMENTOS}

Agradeço, especialmente, as valiosas contribuições do meu orientador, Gilson Rambelli, que, juntamente com os arqueólogos especialistas em ambientes aquáticos Leandro Duran e Paulo Bava de Camargo, colaboraram intelectual e científicamente para minha pesquisa de mestrado. Ao arquelógo, também especialista em ambientes aquáticos, Flávio Calippo, agradeçoas contribuições proferidas por ocasião da defesa de minha dissertação. Quero manifestar aqui a minha gratidão e agradecimento à equipe do Laboratório de Arqueologia de Ambientes Aquáticos (LAAA/UFS) pela ajuda e apoio nos debates intelectuais e na lida diária das atividades de campo de um pesquisador. Por fim, agradeço à Marinha do Brasil, que por meio da Diretoria do Patrimônio Histórico e Documentação da Marinha (DPHDM) e de seus membros, tornou possível e continuam incentivando o desenvolvimento de meus estudos no âmbito do Patrimônio Cultural Subaquático

\section{REFERÊNCIAS BIBLIOGRÁFICAS}

ARAGÃO, Lica Moniz de. Um encontro entre a linguagem visual contemporânea e a Arqueologia Marítima. [blog na internet]. 04 out. 2010. Disponível em: <http://projetomaraldi.blogspot.com.br/>. Acessoem: 22 nov. 2014.

BAUMANN, Timothy. Local History. In: ORSER JR., Charles E. (Ed.). Encyclopedia of historical archaeology. London: Routledge, p. 316-319, 2002.

BEZERRA DE ALMEIDA, M. O Público e o Patrimônio Arqueológico: reflexões para a Arqueologia Pública no Brasil. Revista Habitus, Goiânia, GO, 1(1): 275-296, 2003.

CARVALHO, Aline Vieira; FUNARI, Pedro Paulo de Abreu. As possibilidades da Arqueologia Pública [online]. 24 mar. 2009. Disponível em: $<\mathrm{http}: / / \mathrm{www}$.historiaehistoria.com.br/materia.cfm?tb=arqueologia\&id=31>. Acesso em: 18 fev. 2014.

FONTOLAN, Marina. Arqueologia Subaquática, Arqueologia Pública e o Brasil. Revista de Arqueologia Pública, São Paulo, SP, 6: 30-38, 2012. 
FUNARI, Pedro Paulo A. Brazil. In: ORSER JR., Charles E. (ed.). Encyclopedia of historical archaeology. London: Routledge, p. 70-71, 2002.

Arqueologia. 2. ed. São Paulo: Contexto, 2010.

FUNARI, Pedro Paulo A.; OLIVEIRA, Nanci Vieira; TAMANINI, Elizabete. Arqueologia Pública no Brasil e as novas fronteiras. Praxis Archaeologica, 3: 131-138, 2008.

FUNARI, Pedro Paulo A.; ROBRAHN-GONZÁLES, Érika. Editorial. Revista de Arqueologia Pública, São Paulo, n 1, 2006.

SP, 27(2): 13-30, 2008.

Ética, Capitalismo e Arqueologia Pública no Brasil. História, Franca,

FUNARI, Pedro Paulo A.; CARVALHO, A. Patrimônio cultural, diversidade e comunidades. Primeira Versão, Campinas, IFCH/UNICAMP, 2011.

HODDER, I.; HUTSON, S. Reading the past: current approaches to interpretation in Archaeology. 3. ed. United Kingdom: Cambridge University Press, 2003.

JOHNSON, Matthew. Teoría Arqueológica: una introdución.Barcelona: Editorial Ariel, 2000 .

MCKEE, Larry. Public Archaeology. In: ORSER JR., Charles E. (Ed.). Encyclopedia of historical archaeology. London: Routledge, p. 511-514, 2002.

MERRIMAN, Nick. Introduction: diversity and dissonance in public archaeology. In:

(ed). Public Archaeology. London: Routledge, 2004.

RAMBELLI, Gilson. Arqueologia até de baixo d'água. São Paulo: Maranta, 2002.

Arqueologia subaquática do Baixo Vale do Ribeira. Tese de Doutorado em Arqueologia. Faculdade de Filosofia, Letras e Ciências Humanas da Universidade de São Paulo: Museu de Arqueologia e Etnologia da USP, São Paulo, 2003.

Entre o uso social e o abuso comercial: as percepções do patrimônio cultural subaquático no Brasil. História, Franca, SP, 27(2): 49-74, 2008.

Mergulhar para conhecer e divulgar: Arqueologia Subaquática e Cidadania. In: CARVALHO, Aline Vieira de; SOARES, Inês Virgínia Prado; FUNARI, Pedro Paulo A.; SILVA, Sérgio Francisco Serafim Monteiro da (orgs). Arqueologia, Direito e Democracia. Erechim: Habilis, v. 1, p. 257-272, 2009a.

Patrimônio Cultural Subaquático no Brasil: discrepâncias conceituais, incongruência legal. In: FUNARI, P. P. A.; PELEGRINI, Sandra C. A.; RAMBELLI, Gilson (orgs.). Patrimônio Cultural e Ambiental:questões legais e ambientais. São Paulo: Annablume, v. 1, p. 59-76, 2009b.

ROBRAHN-GONZÁLEZ, Erika Marion. Arqueologia e Sociedade no município de Ribeirão Grande, sul de São Paulo: ações em Arqueologia Pública ligadas ao projeto de ampliação da mina calcária limeira. Revista de Arqueologia Pública, São Paulo, SP, 1: p. 63-120, 2006. 
SILVA, B. S. R. Pérolas, caçadores e coletores: alguns apontamentos sobre arqueologia pública e arqueologia subaquática no Brasil. Vestígios. Revista Latino-Americana de Arqueologia Histórica, Belo Horizonte, MG, 4: 65-92, 2010.

TRIGGER, Bruce. A História do Pensamento Arqueológico. Tradução de Ordep Serra. São Paulo: Odysseus, 2004.

WICHERS, Camila Azevedo de Moraes. Patrimônio Arqueológico Paulista: proposições e provocações museológicas. Tese de Doutorado em Arqueologia. Faculdade de Filosofia, Letras e Ciências Humanas da Universidade de São Paulo: Museu de Arqueologia e Etnologia da USP, São Paulo - SP, 2011. 